\title{
PEMBELAJARAN BAHASA INGGRIS UNTUK ANAK-ANAK
}

\author{
Besral \\ Pendidikan Bahasa Inggris Fakultas Tarbiyah IAIN Imam Bonjol Padang \\ Korespondensi: Komplek Puri Lestari, Blok G-11 Parak Laweh Padang, Sumatera Barat
}

\begin{abstract}
A large numbers of credits taken by college students in Undergraduate Program proved to be insufficient for their successful competition in the job market. To deal with this issue, Teacher Training Colleges and Institution provided their graduates with several professional skills related to computer and internet, foreign language learning, and other vocational skills. Some of the results of these programs are fruitful for the graduations; however, several ongoing activities need to be monitored and reviewed. Although 'Hunting Tourists' has been the trade mark of the English Tadris Department, 'Teaching Engish for the Children' which will be implemented in the few years to come, may override the previous ones because of its advantages and practical values.
\end{abstract}

Kata kunci: Praktikum, pembelajaran, pendekatan, metode, strategi, teknik, bahasa Inggris, program.

\section{PENDAHULUAN}

M ata kuliah 'Teaching English for the Children' (Pembelajaran Bahasa Inggris untuk Anak-Anak) adalah salah satu mata kuliah pilihan wajib di Jurusan Tadris Program Studi Bahasa Inggris, Fakultas Tarbiyah IAIN Imam Bonjol Padang (Revisi Kurikulum, 2007). Mata kuliah ini diberikan sejalan dengan program Peningkatan Kualitas Akademik Mahasiswa. Mata kuliah yang sama juga diberikan kepada mahasiswa program D2 dan S1 Guru Kelas Madrasah Ibtidaiyyah (GKMI), namun dimasukkan ke dalam MK yang berbobot 2 sks. Pertanyaannya adalah mengapa mata kuliah ini diberikan kepada mahasiswa S1 Tadris Bahasa Inggris, bukankah 150 sks sudah cukup bagi mereka? Apa sasaran yang hendak dicapai Jurusan/Prodi dengan mata kuliah seperti ini? dan Bagaimana metode atau prosedur perkuliahannya?.
Tulisan ini bertujuan untuk (1) memberikan alasan teoritis dan praktis dimunculkannya mata kuliah Pembelajaran Bahasa Inggris untuk AnakAnak; (2) mendeskripsikan model/rancangan pembelajaran bahasa Inggris di Sekolah Dasar yang ideal dan implementasi metode atau prosedur pembelajarannya; serta (3) mengungkapkan beberapa hasil penelitian sehubungan dengan diberlakukannya pembelajaran Bahasa Inggris di Sekolah Dasar di Kota Padang. Pada bagian akhir artikel ini juga akan disajikan metode dan prosedur perkuliahan/ pratikum dimaksud.

\section{TINJAUAN PRAKTIS DAN TEORI- TIS PEMBELAJARAN BAHASA INGGRIS PADA ANAK USIA DINI}

Ada dua asumsi pokok yang mendasari pemilihan mata kuliah ini sebagai Mata kuliah Praktikum, yaitu alasan praktis dan teoritis. Alasan praktis meng- 
acu kepada pengembangan sikap kewirausahaan, manajerial, dan etos kerja. Sedangkan alasan teoritis dikemukakan sesuai dengan bidang kajian keilmuan yang dikembangkan di Jurusan Tadris Bahasa Inggris, yaitu mata kuliah yang terkait dengan pembelajaran Bahasa Inggris seperti: Curriculum Development and Instructional Program, Classroom Management, Analysis of Madrasah Aliyah/Ibtidaiyyah Curriculum and Textbooks, TEFL Methodology, ELT Techniques, Psycholinguistics dan Evaluation.

\section{Pertimbangan Praktis}

Pemerintah daerah Sumatera Barat telah menetapkan bahasa Inggris sebagai pelajaran muatan lokal di Sekolah Dasar. Sebagian sekolah merekrut tenaga pengajar dari lembaga kursus, sementara yang lain menggunakan guru kelas atau guru bidang studi lain yang dianggap mampu mengajarkan bahasa Inggris. Beberapa sekolah bahkan mendatangkan guru asli bahasa Inggris dari sekolah lain yang berdekatan. Kecenderungan seperti ini seharusnya telah diantisipasi oleh Perguruan Tinggi seperti FKIP dan Fakultas Tarbiyah.

Ketidaksiapan Perguruan Tinggi dalam menanggulangi kebutuhan akan guru Bahasa Inggris di Sekolah Dasar bisa dimaklumi. Menurut penulis hal ini disebabkan karena, Pertama, Perguruan Tinggi Keguruan saat ini sudah fokus kepada jenjang sarjana (S1), (S2) dan (S3), yang secara prinsip tidak lagi berorientasi kepada pendidikan dasar, akan tetapi ke jenjang pendidikan menengah. Kedua, banyak para sarjana berpendapat bahwa mengajar di jenjang Sekolah Dasar kalah pamor jika dibandingkan dengan mengajar di sekolah lanjutan. Dengan demikian, dapat dipastikan jika honor atau penghasilan yang diperoleh jauh lebih kecil (hal ini tentu saja memerlukan bukti yang kongkrit atau sahih!). Namun dengan tinggi- nya permintaan (demand) dari masyarakat saat ini, Jurusan Tadris Bahasa Inggris di Fakultas Tarbiyah IAIN Imam Bonjol Padang harus segera melakukan tindakan, yakni dengan membekali mahasiswa dengan keterampilan perihal pembelajaran Bahasa Inggris untuk anak-anak.

\section{Pertimbangan Teoritis}

\section{Pembelajaran di Usia Dini}

Pembelajaran bahasa Ingris yang dimulai dari kelas 4, 5, dan 6 di SD (kurang lebih usia 10-11-12 tahun) perlu dicermati oleh guru dengan sebaikbaiknya. Anak-anak pada usia ini memiliki kemampuan yang tinggi untuk memperoleh bahasa lewat pajanan terhadap bahasa itu, misalnya melalui melihat dan menyimak, selain melalui pengajaran tradisional. Oleh karena itu tugas guru adalah menyediakan kesempatan sebanyak mungkin agar pemerolehan ini terjadi. Mereka juga belajar dengan mempraktekkan bahasa, yakni dengan mendengarnya, mengatakannya, membacanya, dan menuliskannya, bahkan mungkin memimpikannya (Alwasilah, 2000:88).

Mereka belajar cepat manakala mereka termotivasi untuk belajar. Salahsatu cara agar mereka tetap termotivasi antara lain adalah dengan mengupayakan agar kegiatan pembelajaran tetap menarik bagi siswa. Guru sebaiknya mengupayakan agar siswa dapat melihat langsung hasil prestasi mereka (misalnya dengan menempelkan hasil karyanya di papan tempel). Upaya guru juga harus ditujukan bagaimana melibatkan siswa dalam kegiatan yang relevan dengan dunia mereka, yakni dengan memperhatikan minat, pengalaman, latar belakang, dan lingkungan mereka.

\section{Prinsip Pembelajaran Bahasa}

Ada sejumlah prinsip pembelajaran bahasa yang dapat dijadikan rujukan teoretis dalam mengembangkan kuri- 
kulum, bahan ajar, strategi belajarmengajar, dan mengelola kelas bahasa di SD (Alwasilah, 2000: 92). Prinsip-prinsip tersebut mengandung muatan communicative approach (pendekatan komunikatif) dan nuansa meaningfulness (kebermaknaan). Prinsip-prinsip tersebut adalah:

1. Yang nyata yang bermakna. Menurut Piaget (1955), kognitif anak-anak SD berada pada tahap operasional kongkrit di mana mereka belajar melalui pengalaman langsung atau learning by doing dengan memanfaatkan objek selingkung. Dalam pembelajaran bahasa Inggris, anak-anak SD seyogyanya diaktifkan secara fisik, dan bahasa Inggris hanyalah bagian dari aktivitas ini. Dengan kata lain, aktivitas ini dibermaknakan melalui bahasa Inggris.

2. Ramai-ramai main bahasa. Vygostky (1981) menggagas bahwa anak-anak belajar melalui interaksi dalam konteks sosial, dalam kelompoknya. Dalam setiap kelompok selalu ada anggota yang lebih unggul dari anggota lainnya. Anggota unggul ini diberdayakan sebagai fasilitator dengan menarik anggota lainnya agar melangkah maju, jauh menyeberangi batas teritorial kognitifnya. Anggota unggul ini adalah sebaya, dewasa, bahkan sang guru sendiri.

3. Yang sedang-sedang saja. Sejalan dengan prinsip di atas, Krashen (1983) mengajukan konsep comprehensive input, yaitu input atau materi ajar bahasa Inggris yang hinggap pada anak-anak SD dan terpahami. Bagaimana bisa terpahami? Karena materi langsung merupakan bagian tak terpisahkan dari interaksi yang sedang mereka libati. Krashen juga mengajukan konsep i +1 , bahwasanya kualitas materi ajar yang diberikan seyogyanya 'melangkah maju', atau setingkat lebih tinggi dari akumulasi pemahaman yang ada.
4. Salah itu indah. Kemampuan berbahasa seperti dirujuk di atas, menurut Lindfors (1987) diperoleh karena si pembelajar secara aktif menebak-nebak dan menguji coba bahasa. Dengan kata lain, ada kreativitas kognitif dengan cara mengotak atik aturan-aturan bahasa yang sedang dipelajari. Implikasi dari prinsip ini adalah bahwasanya belajar bahasa meniscayakan adanya kesempatan jembar untuk bereksperimen dengan bahasa. Dengan demikian, kesalahan berbahasa mesti diyakini sebagai alami, manusiawi, dan tak terelakkan. Belajar bahasa tidak sekedar pembentukan kebiasaan, melainkan juga nawaitu, kenekadan, uji-coba dan rancage (kreativitas).

5. Adu tawar kata dan makna. Pemerolehan bahasa terjadi karena adanya interaksi sosial, yaitu pemakaian bahasa dalam komunikasi yang otentik. Para pelibat komunikasi beradu tawar pesan komunikasi. Makna yang dipahami sebenarnya dibangun bersama, bukan sepihak (Ellis: 1986); Krashen (1983). Hal ini mengisyaratkan bahwa pembelajar bahasa itu mesti berbicara satu sama lain dalam komunitas kecil untuk berbagi input. Tidaklah mungkin seseorang dapat belajar bahasa dengan mengisolasi diri, menjauhi pembelajar lain.

\section{Komponen Pembelajaran Bahasa}

Bahasa terdiri dari dua komponen yaitu ilmu/pengetahuan (knowledge) dan keterampilan (skills). Komponen pertama terdiri dari tata bahasa (grammar), kosa kata (vocabulary), ejaan (spelling), lafal (pronunciation). Komponen kedua adalah keterampilan berbahasa, mencakup menyimak (listening), berbicara (speaking), membaca (reading), dan menulis (writing). Seberapa banyak komponen dan keterampilan berbahasa ini diterapkan secara simultan oleh sipemakai bahasa, merupakan cerminan 
seberapa baik pula sipengguna bahasa tersebut dapat berbahasa dengan baik dan benar.

Untuk mengungkapkan gagasan, seseorang memerlukan kosakata yang mungkin tidak terbatas jumlahnya, sesuai dengan tujuan atau sasaran yang hendak dicapainya melalui komunikasi tersebut. Dalam konteks ini, jelas kosakata akan mempengaruhi kelancaran arus komunikasi. Namun demikian, Holden (1996:2) mengatakan bahwa aspek yang paling sulit dalam pembelajaran bahasa adalah justru dalam mengingat kosakata. Oleh karena itu, pemerolehan kosakata secara cepat dipandang sebagai suatu hal yang sangat penting dalam mempelajari bahasa.

Menurut kegunaannya, Haycraft (1994: 44) mengklasifikasikan kosakata ke dalam dua jenis, yaitu kosakata aktif dan kosakata pasif. Kosakata aktif adalah kosakata yang digunakan dalam berbicara dan menulis (productive skill), sementara kosakata pasif adalah kosakata yang digunakan saat menyimak dan membaca (receptive skill). Sesuai dengan prinsip-prinsip sebagaimana diutarakan di atas, maka kosakata yang dibutuhkan anak-anak (SD) tentulah kosakata konkrit.

\section{RANCANGAN MODEL PEMBE- LAJARAN BAHASA INGGRIS DI SEKOLAH DASAR}

\section{Pendekatan (Approach)}

Pendekatan (approach) pembelajaran bahasa adalah sejumlah asumsi, teori dan persepsi tentang bahasa dan belajar bahasa. Dalam perkembangannya, pendekatan dalam pembelajaran bahasa telah banyak mengalami perubahan: mulai dari pendekatan tata bahasa, pendekatan nosi, pendekatan genre, dan pendekatan tema.

Pendekatan tema bermula dari pemilihan topik yang menarik bagi pem- belajar, diikuti dengan desain kegiatan yang akan melibatkan pembelajar dalam menjelajahi tema tersebut dan dengan menggunakan bahasa Inggris sebagai alat jelajahnya. Diasumsikan bahwa pembelajar akan lebih termotivasi untuk belajar manakala fokus mereka tertuju pada tema yang mereka gandrungi. Tema yang dibangun hendaknya bersifat umum sehingga dapat dikembangkan menjadi berbagai anak tema. Titik tumpu pengembangan tema adalah konsep atau topik yang sesuai dengan kebutuhan siswa dan mewadahi integrasi keempat keterampilan berbahasa.

Sundayana (1998:116) mengemukakan lima tujuan dari penggunaan pendekatan tema, yaitu untuk:

a. Menjamin keterkaitan antara konsep yang tertuang dalam bahan pustaka dengan dunia pembelajar.

b. Menyajikan kepuasan bagi pembelajar karena kesesuaian tema yang dipilih.

c. Menjelajah masalah keseharian pembelajar.

d. Memadukan keempat keterampilan berbahasa.

e. Mengembangkan strategi pengajaran keempat keterampilan berbahasa.

Dalam permainan sesungguhnya desain pengajaran memayungi sejumlah komponen, seperti: sillabus, bahan ajar, prosedur pemilihan dan pengembangan tema. Sillabus hendaknya berpihak kepada pembelajar (bottom-up), di mana guru hendaknya berperan sebagai pendidik, sahabat, pengendali, fasilitator, dan menempatkan pembelajar sebagai subjek, bukan objek.

Bahan ajar dan alat bantu diperlukan untuk mempermudah tugas guru dalam membuat yang jauh menjadi dekat, abstrak menjadi kongkret, mustahil menjadi mungkin. Realia, peta, bola dunia, foto-foto, gambar, flashcard, klipping, kalender, postcard, berbagai perangko dalam dan luar negeri, 
bendera-bendera manca negara, buku harian, adalah sederetan alat pelengkap buku ajar yang bisa dipergunakan guru di kelas. Prosedur pemilihan tema dan pengembangannya adalah proses pemetaan jaringan tema beserta anak tema sebagai batas yang akan dijelajahi dalam kelas. Misalnya dengan memilih tema animals, guru dapat mengembangkan sejumlah anak tema seperti: kinds of animals (classification); physical characteristics of animals; animals habitats; dan animal life cycles.

\section{Beberapa Teknik}

Teknik mengajar adalah strategi, kegiatan,langkah-langkah atau prosedur yang dilakukan guru dalam menyajikan bahan ajar untuk memenuhi atau mencapai indikator-indikator yang telah ditetapkan. Teknik mengajar lebih bersifat operasional, idiosinkratik, individual, situasional, dan kontekstual sehingga sangat beragam. Teknik yang baik untuk mengajar bahasa Inggris di SD belum tentu sama baiknya dengan di tingkat sekolah lanjutan. Sehubungan dengan beberapa prinsip yang telah diutarakan di atas, maka calon guru disarankan untuk mengikuti petunjuk praktis sbb:

a. Anak-anak usia 6 tahun hidup dalam wilayah "keinian" dan "kekinian" (here and now). Rujukan terhadap peristiwa abad silam dan pengalaman imajiner di hutan belantara Afrika tidaklah cocok untuk mereka.

b. Anak-anak memiliki kemampuan yang luar biasa untuk memperoleh bahasa melalui pemajanan, yakni dengan melihat, merasa, meraba, dan mendengar. Tugas guru adalah menyediakan kesempatan pemajanan tersebut.

c. Gunakan bahasa Inggris sebanyakbanyaknya, namun jangan ragu menggunakan bahasa Indonesia bilamana perlu. d. Dalam keseharian respon terhadap ujaran tidak selalu berbentuk respon verbal; karena itu jangan selalu mengharap respon ujar dari pembelajar.

e. Memori anak-anak tidak memungkinkan mereka untuk dapat berkonsentrasi lama, karena itu kegiatan belajar harus bervariasi agar mereka tidak bosan.

f. Anak-anak senang bermain aktif, karena itu biasakanlah mengganti-ganti posisi duduk dan suasana kelas.

g. Usahakan agar pasangan kerja mereka berganti-ganti.

h. Betulkan kesalahan ucapan mereka, namun koreksi itu tidak boleh mengganggu komunikasi apalagi mematahkan semangat mereka.

i. Ciptakan suasana belajar yang menyenangkan dan tanamkanlah pada mereka sikap positif terhadap bahasa Inggris.

Dengan mempedomani butir-butir di atas, guru dapat mengembangkan teknik-teknik mengajar dengan memvariasikan kegiatan-kegiatan seperti disarankan Palim dan Dower (1990) sebagai berikut:

\begin{tabular}{|l|l|}
\hline Jenis Kegiatan & \multicolumn{1}{|c|}{ Contoh } \\
\hline $\begin{array}{l}\text { Coloring and } \\
\text { drawing }\end{array}$ & $\begin{array}{l}\text { Picture square, join- } \\
\text { ing the dots, labelling } \\
\text { cloth, match the } \\
\text { teacher's drawing }\end{array}$ \\
\hline Making things & $\begin{array}{l}\text { Making the boat, } \\
\text { making a television } \\
\text { set }\end{array}$ \\
\hline $\begin{array}{l}\text { Games with } \\
\text { movement }\end{array}$ & $\begin{array}{l}\text { Numbers game, word } \\
\text { recognition games, } \\
\text { shopping games }\end{array}$ \\
\hline $\begin{array}{l}\text { Stories and } \\
\text { speakingactivities }\end{array}$ & $\begin{array}{l}\text { Answer a riddle, } \\
\text { going shopping, fun } \\
\text { with animals }\end{array}$ \\
\hline Writing activities & $\begin{array}{l}\text { Alphabet tree, making } \\
\text { up words, crosswords }\end{array}$ \\
\hline $\begin{array}{l}\text { Discovery } \\
\text { activities }\end{array}$ & $\begin{array}{l}\text { Putting my toys away, } \\
\text { what's missing? }\end{array}$ \\
\hline $\begin{array}{l}\text { Songs, rhymes } \\
\text { and chants }\end{array}$ & My ABC \\
\hline
\end{tabular}


Quizzes, games

and puzzles
Pitograms, multiplication square, what does it mean?
Implementasi dari pendekatan dan teknik di atas dapat dikongkritkan melalui diagram berikut:

Tabel 1. Variasi kegiatan pembelajaran bahasa Inggris di Sekolah Dasar

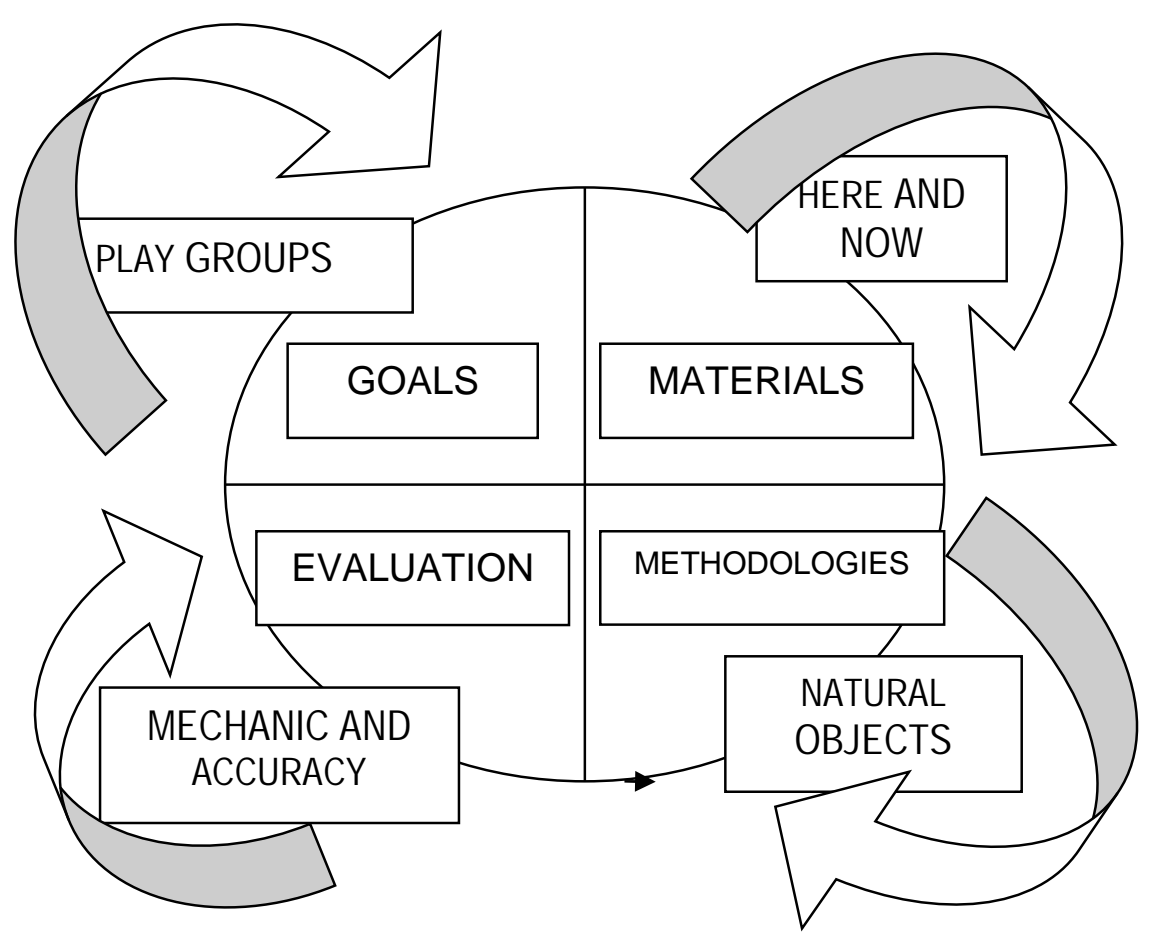

Gambar 1. Pendekatan dan teknik pembelajaran bahasa Inggris di Sekolah Dasar

\section{Peningkatan kualitas Pembelajaran Bahasa Inggris di SD Kota Padang}

Pembelajaran Bahasa Inggris di SD Kota Padang saat ini masih dalam kategori uji coba, meskipun prakteknya telah berlangsung lebih kurang sepuluh tahun. Hali ini terlihat dari belum adanya komitmen yang utuh baik dari kalangan birokrat, maupun dari kalangan praktisi atau guru sendiri. Hingga saat ini, belum ada kurikulum yang baku, materi atau bahan ajar yang dipakai guru tergantung kehendak sipenulis buku teks (yang pada umumnya berasal dari pulau Jawa). Guru karbitan masih sering dan mudah ditemukan di setiap sekolah. Kebanyak- an pihak sekolah menganggap bahwa mata pelajaran Bahasa Inggris adalah indikator dari suatu sekolah yang bonafid, plus, dan lain sebagainya.

Kondisi objektif yang ditemui di lapangan, sebagaimana dilaporkan Amir (2007) dan Syarif (2007) mengungkapkan bahwa dalam berbagai kasus atau sekolah tertentu ada siswa yang justru mengajarkan gurunya (dalam pelafalan). Di lain pihak, ada kecendrungan semakin banyaknya guru-guru kelas yang berminat untuk mengajarkan bahasa Inggris di tempat mereka mengajar. Bentuk-bentuk pelatihan yang pernah diperoleh para guru tersebut mungkin bervariasi, namun pelatihan terprogram selama 1 bulan kelihatannya tidak banyak membantu mereka (Amir, dkk., 1997). Di samping itu, Pelatihan materi 
ajar yang diberikan kepada 20 orang guru SD melalui penyajian, pelatihan, dan monitoring, tampaknya juga belum membawa hasil yang memuaskan (Syarif, 2007).

Tipologi pembelajaran para guru bahasa Inggris di SD, seperti diungkap oleh penelitian tersebut di atas menggambarkan bahwa: (1). Pembelajaran hanya fokus kepada vocabulary saja tanpa menghubungkannya dengan konteks dan vocabulary sebelumnya; (2). Pembelajaran cenderung dimulai dengan menuliskan ejaan dan terjemahannya di papan tulis; (3). Guru kurang/ tidak menggunakan media dalam pembelajaran bahasa Inggris; dan (4). Guru menggunakan buku sumber yang amat beragam, meskipun mereka telah diberi buku "Start" (terbitan FBSS-UNP) secara cuma-cuma.

\section{TUJUAN DAN SASARAN PROGRAM}

Berdasarkan permasalahan yang dihadapi oleh sebagaian besar Sekolah Dasar dan Pemerintah Kota di Sumatera Barat, khususnya Kota padang, maka Jurusan Tadris Bahasa Inggris menawarkan Mata kuliah 'Teaching English for the Children' (Pembelajaran Bahasa Inggris untuk Anak-Anak) dengan tujuan sebagai berikut:

1. Membekali mahasiswa (Jurusan TBI) dengan berbagai pengetahuan dan keterampilan yang mencakup: disain kurikulum, pengembangan materi (bahan ajar), media, metode pembelajaran, dan teknik evaluasi dalam pembelajaran Bahasa Inggris di Sekolah Dasar (SD) atau Madrasah Ibtidaiyyah (MI).

2. Memberikan pengalaman awal kepada mahasiswa perihal proses belajar mengajar Bahasa Inggris sebelum mereka diterjunkan ke lapangan melalui Program Pengalaman Lapangan (PPL).
Seperti mata kuliah biasanya, program ini juga dilaksanakan dalam 15 minggu dengan prosentase $40 \%$ teori dan $60 \%$ praktek. Pemberian teori yang dibarengi dengan praktek atau presentasi mencakup disain kurikulum, pengembangan materi (bahan ajar), media, metode pembelajaran, dan teknik evaluasi dalam pembelajaran Bahasa Inggris.

\section{KESIMPULAN}

Berdasarkan alasan teoretis dan praktis tentang pentingnya pembelajaran bahasa Ingris di SD, maka Jurusan Tadris Bahasa Inggris pada Fakultas Tarbiyah IAIN Imam Bonjol Padang dan PTAI lainnya sudah selayaknya memperkaya khasanah keilmuan. pedagogis mahasiswa dengan mata kuliah "Pembelajaran Bahasa Inggris untuk AnakAnak" (Teaching English for the children). Model rancangan pembelajaran bahasa Inggris untuk anak-anak seyogyanya didasarkan kepada minat dan kebutuhan sipembelajar, dan oleh karena itu, perkuliahan (pratikum) yang akan diberikan kepada mahasiswa harus mencakup pengembangan profesionalisme guru seperti kompetensi profesional, pedagogik, sosial dan kepribadian.

\section{DAFTAR RUJUKAN}

Alwasilah, AC., Perspektif Pendidikan Bahasa Inggris di Indonesia Dalam Konteks Global, (Bandung: CV Andira, 2000) h. 80-97

Amir, Zainuddin, dkk., Pelaksanaan Pengajaran Bahasa inggris di Sekolah Dasar Kotamadya Padang. Dalam Syarif, Hermawati. Peningkatan Kualitas Bahasa Inggris Guru Sekolah Dasar di Kota Padang Melalui Pelatihan Singkat, (Padang: Lingua Didaktika, Vol. I, Ed I, No. 1 Des. 2007, FBSS, Universitas Negeri Padang) h. 26 
Brumfit, Christoper, Moon, Jayne dan Tongue, Ray, Teaching English to Children: From Practice to Principles, (China: Thomas Nelson and Sons Ltd. 1994) h. 24

Ellis, Rod, Understanding Second Language Acquisition, (UK: Oxford University Press, 1986).

Haycraft, John, An Introduction to English Language Teaching. (Singapore: Longman Group Ltd., 1994) h. 44

Holden, William R, 1996, Warms-Up, English Teaching Forum. Dalam Syarif, H. 2007. Peningkatan Kualitas Bahasa Inggris Guru Sekolah Dasar di Kota Padang Melalui Pelatihan Singkat, (Padang: Lingua Didaktika, Vol. I, Ed I, No. 1 Des. 2007, FBSS, Universitas Negeri Padang) h. 27

Krashen, Stephen D. 1983. Principles in Second Language Acquisition. Dalam Syarif H. 2007. Peningkatan Kualitas Bahasa Inggris Guru Sekolah Dasar di Kota Padang Melalui Pelatihan Singkat, (Padang: Lingua Didaktika, Vol. I, Ed I, No. 1 Des. 2007, FBSS, Universitas Negeri Padang) h. 29

Lindfors, Ronald F, 1987, Plannining for spontaneity. Dalam Alwasilah, AC, Perspektif Pendidikan Bahasa Inggris di Indonesia Dalam Konteks Global, (Bandung: CV Andira , 2000)
Palim, John dan Paul Power, 1990, Jamboree: Communication for Children. Hongkong: Thomas Nelson and Sons Ltd. Dalam Alwasilah AC. Perspektif Pendidikan Bahasa Inggris di Indonesia Dalam Konteks Global, (Bandung: CV Andira, 2000) h. 97

Piaget, J. The Language and Thought of the Child, (New York: Meridian Books, 1955) h. 92

Revisi Kurikulum Fakultas Tarbiyah, Lokakarya Kurikulum, (Bukittinggi, 2007).

Sundayana, Wachyu, 1998, Pengajaran Bahasa Berdasarkan Tema. Dalam Alwasilah, ed. Perspektif Pendidikan Bahasa Inggris di Indonesia Dalam Konteks Global, (Bandung: CV Andira , 2000) h. 115-133.

Syarif, Hermawati, Peningkatan Kualitas Bahasa Inggris Guru Sekolah Dasar di Kota Padang Melalui Pelatihan Singkat, (Padang: Lingua Didaktika, Vol. I, Ed I, No. 1 Des. 2007, FBSS, Universitas Negeri Padang) h. 26-32

Vigostky, Semenevich Lev, 1981, Thought and Language. Dalam Alwasilah, AC. Perspektif Pendidikan Bahasa Inggris di Indonesia Dalam Konteks Global. (Bandung: CV Andira, 2000) h. 92

\section{Daftar indeks}



belajar16, 14, 13,12,11,

Guru18,17,16,12,1,

mahasiswa17, 16,1,

materi16, 12,

pembelajaran $17,16,15,13,12,11,1$,
Praktikum11,1, pratikum17, 1,

Sekolah18,17,16,15,11,1, siswa16, $13,12,1$,

strategi14, 12, 1, 